\title{
Entre palos y piedras: La reformulación de la etnicidad en Rapanui (Isla de Pascua 1966)
}

Alejandra M. Grifferos A. ${ }^{2}$

\section{RESUMEN}

Los recientes estudios antropológicos sobre la cultura Rapanui no consideran las relaciones interétnicas como objeto de investigación. Durante las últimas centurias una serie de acontecimientos sociales han configurado la llamada etnicidad rapanui. Uno de esos eventos ocurrido en la Isla de Pascua en diciembre de 1966, adquirió el carácter de conflicto por el grado de interés que generó, tanto en la prensa como al interior de la comunidad. La tradicional llegada del Gobernador a la Isla caracterizada con la entrega de flores, bailes típicos y una gran camaradería, fue reemplazada por insultos, piedras y atropellos. La fuerza pública intervino y mujeres rapanui fueron apaleadas por carabineros. El análisis de este conflicto guarda relación con las estrategias, tácticas, intereses y posiciones de los diversos actores involucrados de manera de visualizar los elementos que legitiman la etnicidad rapanui. La metodología utilizada consiste en un análisis de un expediente judicial, el que junto a testimonios entregados por los isleños, nos podría ayudar a constatar futuros conflictos.

\footnotetext{
ABSTRACT

Recent anthropological studies of rapanui culture have not considered in depth the subject of interethnic relations. During the lasts centuries, a series of events occurred that form part of the social framework that shapes the so-called "Rapanui ethnicity". Such is the case of an event that occurred on the Island in december 1966 which had the character of "conflict" due to the level of interest that it generated in the mainland press, and also in the community itself. The traditional arrival of the Island Governor, usually characterized by receiving a flower lei, with authentic music in the background and great camaraderie, was replaced by insults to the Governor and the throwing of stones. The police intervened, and some island women were beaten with police batons. An analysis of the conflict will
}

be approached from the point of view of the strategies, tactics, interests and positions of those involved in a manner that will permit us to detect the elements that have legitimized rapanui ethnicity. The methodology consists of an analysis of the judicial expedients carried out in a manner that contrasts with the collected testimonies of the islanders, with the expectation of anticipating future conflicts on the Island.

\section{Introducción}

En abril del año 2000 un diario de la capital anunciaba un tenso clima antichileno en Rapanui, que amenazó con una toma de terrenos por parte de los isleños si no se aclaraba el traspaso encubierto de tierras a empresarios no indígenas. Esta situación quizás un poco desconocida en el continente se llevó a cabo mediante la colaboración de ciertos isleños que prestaron sus nombres para las operaciones, a cambio de dinero o bienes.

¿Qué motivó a los rapanui a provocar tal acción, alterando el orden y la tranquilidad de la Isla? ¿Es quizás el deseo de manifestar un estado de inconformidad frente a la no respetada Ley Indígena? No es primera vez que se manifiesta una actitud de rechazo hacia el Estado chileno por parte de la comunidad. A mediados de los años ' 60 del pasado siglo, la administración de la Isla se debió reformar, entre otros factores, por la constante tensión que adquirió la situación colonial en Rapanui.

La década del '60 está marcada por diversas transformaciones ya sean políticas, socioeconómicas y

1 Este artículo es parte de la investigación que realizamos en Rapanui y en los archivos y bibliotecas chilenas, para desarrollar nuestra Tesis de Licenciatura en Historia como también la Tesis para optar al grado de Magister en Antropología y Desasarrollo de la Universidad de Chile.

2 Escuela de Educación, Universidad de Ciencias de la Informática, Santiago. Email: agrifferos@entelchile.net 
culturales, el escenario tanto mundial como nacional se disponía a esperar un nuevo cambio, en el que Rapanui también sería protagonista, ella no podía estar ajena a esta "revolución silenciosa" que se estaba gestando.

Una vez implementada la administración civil en la Isla, los conflictos no cesaron, siendo de particular importancia el movimiento protagonizado por mujeres rapanui en diciembre de 1967, en que la llegada del Gobernador a la Isla despertó las más airadas manifestaciones de rechazo por parte de un sector preponderantemente femenino, provocando desorden, violencia, siendo las mujeres apaleadas por carabineros.

La interpretación y análisis de este movimiento, el que hemos contextualizado en una situación política hegemonizada por la acción de autoridades gubernamentales de la Isla, forman parte del objetivo de este artículo. Intentaremos determinar las distintas perspectivas que emanan del proceso judicial que se aplicó a los isleños involucrados. Sostenemos la tesis de que este movimiento se sustenta en un proceso de "rapanuización" que estaba caracterizando a Rapanui desde principio de esa década.

El análisis de este hecho desde una perspectiva antropológica, permitirá profundizar una línea de investigación en torno a la cultura rapanui y su respuesta frente a este tipo de fenómenos que producen cierto "ruido". En este trabajo se intentará determinar los elementos de etnicidad presentes en el mundo isleño, los cuales les ha permitido generar una identidad propia. Además de contrastar la visión continental y rapanui sobre este acontecimiento, se intentará establecer las posiciones, los intereses, las estrategias y las tácticas de los diversos ac-

3 Un titular de prensa de aquella época, describió de esta manera los sucesos que se estaban llevando a cabo en Rapanui a la llegada del Gobernador.

4 El análisis etnohistórico y antropológico de la cultura rapanui requiere de una periodificación que pernita aislar la trama del contex to colonial que caracterizó a Pascua durante más de un siglo (1864-1964). El punto central es aquí la aprehensión de los esquemas de dominación que significaron un moldeamiento y disciplinamiento de los rapanui. Para efecto de análisis distinguiremos tres momentos en la situación colonial de Pascua: el Colonialismo Misional de 1864 a 187; Colonialismo Empresarial de 1895 a 1953; y Colonialismo Naval de 1953 a 1964. tores involucrados, en la medida de comparar y establecer diferencias en el discurso isleño como portador de las demandas en Rapanui.

El movimiento de las mujeres se legitimó en una tradición comunitaria largamente formulada durante las últimas décadas del siglo XIX. Tradición que da cuenta de la percepción que tuvieron los rapanui de la situación colonial ${ }^{4}$ y de la creación de una etnicidad que tiene tal vez poca relación con un ámbito cultural pre-colonial.

La argumentación que hemos desarrollado se fundamenta en los replanteamientos realizados por la etnohistoria y la antropología en las últimas décadas. Ellos están ligados a la revisión de los modelos que habían predominado para el estudio de los grupos étnicos en contextos coloniales.

El estudio de los movimientos y levantamientos que hubo en Rapanui contra los administradores coloniales y una situación colonial que era experimentada como un menoscabo de la integridad comunitaria, marca un precedente para los futuros conflictos que se llevarán a cabo en Rapanui. Este enfoque polariza la atención sobre factores que habían sido ignorados o subestimados por la bibliografía existente sobre Rapanui. Si bien, la historia, la arqueología, la lingüística, entre otras disciplinas, se han dedicado minuciosamente a describir e indagar en sus prácticas y modos de vida, la gran cantidad de bibliografía se torna escasa cuando intentamos realizar un análisis antropológico que de cuenta de ciertos hechos que han trastocado el mundo isleño.

Acá enfatizaremos la integración de los isleños a la vida nacional, como una variable que transformará el escenario de la isla considerando que:

"se han ido produciendo cambios en el juego de roles de los miembros de la cultura de Isla de Pascua, cambios que traen consigo la adhesión a nuevos valores y patrones de comportamiento que, en gran medida, entran en conflicto con los roles tradicionales ya internalizados por la costumbre" (Silva 1980:27).

Se examinará además cómo este tipo de movimiento, como el ocurrido en 1967, ha sido capaz de introducir cambios radicales en la estructura social, económica y política de la Isla. El poder establecer el motor central que origina los conflictos en Pascua, nos permitiría predecir futuros movimientos. 
La reformulación de la etnicidad

El concepto de etnicidad es relativamente nuevo, la bibliografía especializada data de la década de los años ' 70 . Se comprende bajo la denominación de cultura, es decir,

"cualquier unidad sociocultural, en verdad a cualquier término que describe estructuras particulares asumidas por el flujo de relaciones sociales, se le puede aplicar actualmente el término étnico" (Abercrombie 1991: 197).

En el caso de Rapanui, entendida como sistema cultural, la etnicidad "siempre tiene su génesis en fuerzas históricas específicas las cuales son a la vez estructurales y culturales" (Comaroff cit. por Abercrombie 1991: 201). Por el contrario, la etnicidad rapanui debe ser analizada históricamente y, como ha planteado Devalle,

"las identidades colectivas no existen en forma pura y fija sino que se forjan a partir de una multiplicidad de elementos interrelacionados susceptibles de modificación en el curso del tiempo" (1992:40).

Sin ignorar ni desmerecer la importancia de los enfoques psicologistas en antropología, aquí trataré de esbozar un acercamiento más estrictamente antropológico al problema de la identidad étnica, entendiendo la identidad como "un fenómeno que emerge de la dialéctica entre individuo y sociedad" (Berger y Luckmann 1971: 195). Al ser formada por procesos sociales,

"una vez cristalizada es mantenida, modificada o, incluso, remodelada por las relaciones sociales. Los procesos sociales involucrados en la formación y en el mantenimiento de la identidad están determinados por la estructura social" (Berger y Luckmann 1971: 194).

Es importante resaltar el hecho que para Isla de Pascua, 1864 marca una ruptura en los criterios de identidad. Hay que cuestionarse, ya desde esa época, cómo se articula toda una tradición a través de elementos dejados por el espacio colonial misional; cómo los misioneros entregaron una serie de criterios de identidad que fueron incorporados a la comunidad, y lo más importante, que fueron sentidos y percibidos como propios. En los contextos coloniales los problemas de la identidad son de otra ín- dole. Si suponemos que se producen quiebres o discontinuidades en los discursos de identidad, entonces ahora habría que preguntarnos ¿Cómo se reformularía el problema de la identidad?

Retomando el planteamiento de Adams (cit. por Ruvalcaba 1995), hay dos conceptos de identidad étnica que se refieren no meramente al aspecto subjetivo y objetivo del fenómeno, sino a dos fenómenos diferentes, es decir, la definición de identidad étnica que se da el grupo a sí mismo y la definición que se da al grupo desde afuera, corresponde a dos realidades empíricas diferentes.

La conciencia étnica se articula a partir de una clasificación subjetiva del mundo, al modo como actúan las clasificaciones totémicas propuestas por Lévi-Strauss (1964), es decir, que el sujeto situado en algún lugar comienza a distinguir y a clasificar el mundo que le rodea. Es posible que en la dialéctica de las clasificaciones, se pueda ir incorporando una serie de elementos extraños, pero el punto es que llega un momento que ya no es posible distinguir lo "otro". Entonces lo "otro" es siempre considerado invasor o extraño, habiendo un cierto etnocentrismo detrás de la formulación de una cierta "conciencia étnica", por ejemplo, en el caso mapuche uno puede seguir distinguiendo al otro como mapuche, pero llega un momento en que el otro ya no es mapuche es winca, es extraño, es invasor.

En el mundo rapanui, el Tangata (hombre) es un gran criterio de clasificación, al igual que el tatuaje, pero llega un momento que hay sujetos que no están tatuados, por tanto ¿qué son? Por otra parte, para los grupos que están subordinados hay primeramente una suerte de alineación que implica una pérdida de algo, la pérdida de un espacio propio y a la par de esto, la construcción de una identidad que no puede tener ninguna relación con el ámbito cultural previo a su subordinación. En contextos de subordinación se crea al interior de estos grupos subordinados, una nueva conciencia étnica.

Por tanto, retomando el planteamiento de Bonfil (1988: 86), en Rapanui, al igual que en el resto de América Latina, la condición de indio es la condición de colonizado, con todas las implicaciones correspondientes; es una categoría supraétnica en la que se agrupan pueblos diferentes porque tienen en común el haber sido sometidos a la dominación co- 
lonial que se inició en el siglo XVI.

Aquí importa destacar no tanto los esquemas de dominación colonial como el proceso de hegemonía cultural, que permitió a los rapanui situarse como sujetos protagónicos y como agentes activos frente a lo que consideraban como un menoscabo de sus justos derechos.

En tanto, los levantamientos y movimientos que caracterizaron un cierto tipo de relación de los rapanui con la situación colonial, no deben ser analizados como desprovistos de un cuerpo coherente de doctrina que los legitimen, ni tampoco, como una reacción espasmódica, espontánea y desorganizada de grupos, "empobrecidos culturalmente".

En los levantamientos y movimientos que han sacudido a Pascua, algunos observadores han insistido en la idea de que han sido motivados por la "excitación de los nativos", por nimiedades, por cosas triviales, y esto se debería a que no habría ningún trasfondo en ellos. En el caso de los levantamientos de fines del siglo pasado al apropiarse de los canales de dominación, muchas veces, esto significó una resistencia abierta a las pretensiones de dominación del colonialismo empresarial y posteriormente naval. El fenómeno de una comunidad que se va creando en el contexto colonial, constituye un elemento que va a legitimar los levantamientos de la comunidad frente a los agentes colonizadores.

Tras estos levantamientos, hay una "noción legitimante", mediante la cual los rapanui creen estar defendiendo un "orden moral"s que era apoyado ampliamente por la comunidad, y el que había sido sancionado en un primer momento por los misioneros, luego por la Compañía Explotadora y posteriormente por la Armada.

\section{Del discurso a la acción}

Durante la década de los años ' 60 del pasado siglo, tres importantes acontecimientos se apropiaron del

5 El orden moral apunta, siguiendo a Redfield "a la naturaleza de los vínculos que existen entre los hombres, más que a una categoría del contenido de la cultura. El orden moral comprende los sentimientos vinculadores de lo recto que encontramos en la religión, la solidaridad social que acompaña al ritual religioso, el sentido de seriedad religiosa y del deber que robustece a los hombres y los efectos de una creencia en seres invisibles que la bondad encarna. El orden moral se nos torna vivido cuando los miembros de una pandilla de muchachos se niegan incluso ante las amenazas de la policía, a delatar a un compañero" (1963: 37). espacio isleño: la instalación de una expedición médica canadiense, la apertura al mundo del transporte aéreo, permitiendo conectar la Isla con el mundo exterior, y la instalación de una base norteamericana.

La expedición médica canadiense (METEI) llevaba un tiempo en la Isla realizando diversas investigaciones, como forma de constatar los cambios que se producen al interior de una comunidad indígena (véase Evans 1965, McCall 1994 a y b, Porteous, 1981). Los rapanui recuerdan que esta expedición les trajo medicamentos y llevó a cabo una serie de operaciones quirúrgicas en la población isleña.

En tanto, sobre la base de un convenio originado durante el gobierno de Jorge Alessandri, entre la Fuerza Aérea de Chile (FACH) y la US Air Force (USAF), se inician los estudios y trabajos para la instalación de una base rastreadora de satélites en la Isla. La base instalada en 1965, fue desmantelada en $1970^{6}$ una vez que asume el gobierno del Presidente Salvador Allende, el cual un año antes visitó la Isła en calidad de Senador y solicitó visitar la base, la cual le negó el acceso argumentado que era un recinto militar y sólo ingresaban personas pertenecientes a ella. Allende una vez que asumió el poder, ordenó cancelar dicho convenio.

El acceso a los bienes y servicios traídos por los norteamericanos despertó gran revuelo en una comunidad tan pequeña y enraizada en las costumbres ancestrales como lo era Rapanui. ${ }^{7}$ A juicio de Cristino y colaboradores

6 La percepción isleña respecto a este hecho, marca el énfasis en la negativa de la USAF al entonces senador Salvador Allende: "En 1968 vino a la Isla, el Senador Allende acompañando a un grupo de asilados políticos por el asunto del Che Guevara, se trasladaron a la Isla. En Papeete iban a tomar vuelo a la Rusia. Yo conversé con él y quiso Allende ir a conocer la base y yo le dije que no había ningún inconveniente. En la tarde se encontró con el Comandante chileno para pedirle autorización y el Comandante norteamericano le dijo que no. Cuando asumió, ellos se fueron se pusieron a la defensiva" (Alfredo Tuki, febrero de 1996).

7 Los rapanui recuerdan "que los norteamericanos tienen el poder económico, en todo momento. Ese mismo hecho, en una población tan reducida, tenía que trascender". En la semana los gringos tenían una bodega inmensa, donde la población iba a bailar y a tomar, ellos mismos los recolectaban en las micros que ellos tenian. La Isla entera iba a bailar, yo nunca fui. Hubo muchos excesos, instalaban grupos de guerra, te regalaban dólares, ganaban dólares (testimonio, véase Grifferos 1997). 
"durante este periodo, los isleños tuvieron la oportunidad de vivir el mundo del desarrollo y al mismo tiempo, el poder hacer comparaciones con el continente, las que fueron en desmedro de este último" (1984: 30).

Otro fenómeno de la base norteamericana es su marcada influencia sobre la mujer rapanui, la que rompe en cierto modo con el matrimonio endogámico y decide emigrar a diferentes lugares, como Estados Unidos, Francia, Alemania, Tahíti, etc., como una forma de buscar nuevos horizontes (véase Cristino et al. 1984, Galleguillos 1974, Delsing et al. 1998).

En octubre de 1964 el poder ejecutivo presentó al Congreso Nacional un proyecto de ley que crea la Comuna Subdelegación de Isla de Pascua y consulta diversas medidas tendientes al desarrollo de la Isla, además el Presidente de la República aceptó las demandas de los isleños, dando a conocer que Rapanui pasaría a depender de la administración civil, lo que se concreta finalmente en 1965.

"Los oficiales fueron autorizados a inaugurar un sistema municipal de gobierno en Hanga Roa. La primera reunión de una Junta de Vecinos oficial tuvo lugar el 16 de marzo de 1966 y la constitución municipal se hizo efecto sólo el 21 de mayo de 1967. Las actas de estas reuniones municipales son públicas y guardaban relación con funciones civiles tan normales como lo son la regulación de vehiculos, los permisos de construcción, venta de licores, sanidad, mercado, precios de las frutas y peces y cosas asi. Sin poder para recaudar impuestos, las autoridades municipales fueron apoyadas por la subvención gubernamental y un porcentaje de los beneficios del casino de Viña de Mar" (Porteous 1981: 172).

Con la instauración de la administración civil, nuevos tiempos se vaticinaban para Pascua, una nueva era de derechos y garantías institucionales comenzarían a regir la vida de los rapanui. Producto de la acción desplegada por la comunidad rapanui, la prohibición de circular libremente por la Isla fue levantada.

En tanto, el Fundo Vaitea y los bienes muebles hasta ese momento administrados por la Armada, son traspasados a la Corporación de Fomento de la Producción (CORFO), y el Hospital pasa a depender del Servicio Nacional de Salud, además se crea el
Departamento Isla de Pascua por Ley 16.441 del $1^{\circ}$ de marzo de 1966 (Ley Pascua). Esta ley otorgó a los isleños el derecho a sufragio universal largamente esperado,

"es un hito importante para los rapanui, ya que en ella, por primera vez en el marco de la institucionalidad chilena, hubo una consideración a las costumbres existentes, y a las instituciones de orden familiar de nuestro pueblo".

En 1966 se instalan los servicios públicos y la infraestructura administrativa que se cree necesaria, para incorporar la Isla a la vida nacional, no obstante, esta situación fue duramente criticada en aquella época porque

"bastó con la invasión burocrática de cerca de 200 funcionarios, más sus respectivas familias para que cambiara la apacible vida de los isleños. A ello hay que sumar la creación de varios organismos públicos que prácticamente nada tienen que hacer $d u$ rante el año y que se traduce en grandes sueldos, viáticos y grattficaciones de zona que suben del trescientos por ciento" (La Unión 8/1/1967).

Por su parte, la comunidad rapanui no protestó

"contra las determinaciones del gobierno, sino que ello era una justa reacción a lo que ellos estimaban una lesión a sus legítimos derechos que les daba la tradición y herencia de sus antepasados" (Galleguillos 1974: 144).

En otro ámbito, el sistema público implementado en la Isla permite el establecimiento de partidos políticos especialmente de la Democracia Cristiana. Es un período en el que se intensifican las actividades económicas de la Isla y se crean Cooperativas de producción como la Rapanui y la Te Pito Te Henua, que pretendían mantener el sistema tradicional de Rapanui, sin embargo, los intereses de quienes manejan estos organismos, entran en conflicto por el poder y "sumadas a la carencia de asesoría técnica, planificación y formas crediticias, llevan a estas organizaciones al fracaso" (Cristino et al. 1984:32).

El Alcalde Alfonso Rapu ${ }^{8}$, se siente limitado en su gestión por la precariedad de fondos destinados al

8 Alfonso Rapu acrecentó su liderazgo al interior de su comunidad, producto de toda la acción desplegada en el movimiento de 1964. Para mayores detalles de este movimiento veáse Grifferos (1997). 
Municipio. Rapu, con un liderazgo acrecentado en su comunidad no se asocia con las Cooperativas de Gobierno y estimula la permanencia de las Cooperativas isleñas lo cual genera fisuras con el sistema, acusándosele de separatista y antichileno (véase McCall 1976). Más aún la figura de Alfonso Rapu fue cuestionada por el Gobierno Demócrata Cristiano, acusándosele de "marxista" por no compartir dicha ideología, y más aún, por no compartir las ideas del gobernador.

Esta situación se torna crítica a fines de 1966, en que la comunidad rapanui, especialmente las mujeres y el Gobernador Enrique Rogers, serán protagonistas de un nuevo conflicto que provocó un gran revuelo a nivel institucional, político y periodístico, y en el cual intervino la fuerza policial siendo las mujeres agredidas por la fuerza pública. Si hacemos nuestra la noción de Thompson,

"es probable que con mucha frecuencia las mujeres precipitaran los movimientos espontáneos, pero otro tipo de acciones se preparaban con más cuidado" (1984: 171).

No sólo los diarios de oposición, como los de Gobierno informarían una realidad desnudamente disfrazada, sino que esta vez la televisión también sería el fiel testigo de un hecho poco usual en la Isla, pero no el único.

\section{El isleño Alfonso Rapu}

Antes de implementarse la administración civil en la Isla y considerando la prohibición de viajar al continente, un grupo de jóvenes rapanui logró quebrantar esta medida gracias a una autorización que se les concedió a través de la "Sociedad de Amigos de la Isla de Pascua”. La medida se adoptó con el propósito de proseguir los estudios de educación básica, media y superior, respectivamente. En 1957 entre los primeros favorecidos podemos citar a Lucía Tuki, Alfonso Rapu Haoa, Juan Laharoa, Benito Rapahango y Catalina Hey.

En 1964 algunos de estos estudiantes regresan con el título de Profesor Normalista, destacándose Alfonso Rapu, quien en 1963 se recibe en la Escuela Normal "José Abelardo Núñez" de Santiago, siendo designado profesor por el Ministerio de Educación en la Escuela Pública de Hanga Roa. Desde que llegó a la Isla, Rapu se propuso llevar a cabo algunas tareas de adelanto general, caracterizándose por la gran "iniciativa para desarrollar labores de índole social" (La Nación 2/2/65). Pero, ¿en qué legitimó su liderazgo?, ¿qué le permitió a Rapu y no a otro rapanui, convertirse en un prominente miembro de su comunidad?

Una de sus primeras iniciativas fue formar una "brigada de estímulo" con aquellos alumnos que tenían las mayores calificaciones en la Escuela. Alfonso insistió que "el objetivo era recorrer la Isla en forma forestal, era una convivencia a nivel general". También se fundaron cinco clubes deportivos, que impulsaron la práctica del fútbol y básquetbol, además emprendió una serie de iniciativas de urbanización y omato en el poblado de Hanga Roa. Cabe señalar además, que con el fin de rescatar la música autóctona organizó un grupo de cantos y danzas con Luis Paté Tuki, conformado por niños de la Escuela entre 9 y 11 años.

Finalmente propició la idea de crear un museo arqueológico en Hanga Roa, es más, Rapu "quería declarar la Isla como un Museo" (testimonio, véase Grifferos 1997). De esta manera, Rapu se transformó rápidamente en un líder local y decidió dar solución a las inquietudes de los rapanui.

Alfonso Rapu se educó en el continente desde muy temprana edad, y por tanto, "conocía ese mundo diferente" el cual la gran mayoría de los rapanui anhelaba alcanzar. Rapu "quería hacer eso que veía en el continente en la Isla". Al llegar a Pascua, se da cuenta que la Isla necesitaba de una serie de reformas que permitirían a los rapanui "dignificar la integridad" quebrantada por el esquema de colonialismo naval para que "Pascua y sus habitantes tuvieran los mismos derechos".

Las variables mencionadas anteriormente, es decir, el desarrollo urbano impulsado, el mejoramiento de las calles de Hanga Roa, el rescate de la música autóctona y el rescate de la integridad comunitaria, entre otras, constituyen los elementos que permitieron a Alfonso acrecentar su prestigio al interior de la comunidad rapanui, "quise incorporar la Isla a Chile a través de sus actividades". El manifestó que "Ia formación de actividades deportivas y cooperativas de producción, beneficiaba directamente a los más necesitados de la Isla". Cabe destacar, que en todas estas actividades contó con el apoyo de las religiosas y los niños. 
En 1966 su programa como candidato a regidor consistía en que

"toda la población de Pascua sea una sola y trabaje para la Isla. Dice que allí no se necesita política. Quiere que los pascuenses sean unidos entre ellos y que trabajen en conjunto para facilitar el progreso" (El Siglo 5/1/1967).

\section{El Gobernador Enrique Rogers}

Enrique Rogers Sotomayor fue el primer Gobernador Civil de Isla de Pascua, cargo que sólo ostentó por un período aproximado de seis meses. De profesión ingeniero, previo a su designación para Gobernador, se desempeñó como funcionario de la Corporación de Fomento de la Producción (CORFO). ${ }^{9}$

La prensa en aquel entonces retrataba al Gobernador como

"un caballero de la ciudad que debe haber leido mucho a Ruyard Kipling. Se identificó así con un gobernador inglés fiel al Rey, que cumple una misión civilizadora en una colonia de gente violenta a quien hay que ganar para la corona. No mantuvo muchos contactos con los nativos, estos sólo le vieron en contadas ocasiones a pesar de que el territorio de la Isla es pequeño y que es imposible no encontrarse a una hora con todos sus habitantes. Don Enrique pasaba en su cabaña sumido en profundas meditaciones. Su responsabilidad era enorme. Costara lo que costara para convertir a los isleños en unos revolucionarios en libertad. ${ }^{10}$ Tras muchos imperativos fundó el Partido Demócrata Cristiano de la Isla de Pascua. Se ganó además algunos regalitos -- a algunos isleños a quienes convirtió en líderes locales del pensamiento de Jaime Castillo, Jorge Cash y Rogers Vekemans. Se consiguió una buena partida de ejemplares de "La verdad tiene su

9 Enrique Krauss recuerda que "Rogers fue un tipo conflictivo, era una persona que tenía el propósito de lograr un nivel de desarrollo, había sido un muy buen funcionario de la CORFO, la cual había impulsado un proyecto de desarrollo, por eso se le designó gobernador, pero los isleños tenían conflictos con las autoridades del Continente y estos a su vez estaban divididos. Ud. tiene que entender que en una Isla donde no hay televisión, no hay teatro, y además, hay un circuito de superficie muy limitado, terminaba por generarse grupos" (véase Grifferos 1997).

10 "La Revolución en libertad" fue el slogan que usó la Democracia Cristiana durante el proceso eleccionario previo a 1964. La percepción rapanui de este hecho lo asocia a un período de progreso para la Isla. hora" que pretendió convertir en una especie del Coran de la Isla. Personalmente repasó "Humanismo Integral", libro olvidado dentro del cuadro de sus pocas lecturas de juventud" (El Siglo 4/1/ 1967).

Rogers, imitando el sistema de las cooperativas implementado en Rapanui creó algunas que no sobrepasaban a las treinta y cinco personas. No obstante, los rapanui que no estaban ajenos a las medidas implementadas por Rogers, manifestaron que

"estamos organizados en Cooperativas desde hace más de un año, es así como tenemos Cooperativa Pesquera y Agrícola, que se creó a iniciativa exclusivamente nuestra. Con anterioridad se le dio al entonces Coordinador don Enrique Rogers, todos los antecedentes para que gestionara el reconocimiento oficial, lamentablemente hoy todo eso se ha ignorado, intencionalmente se desconoce, ya que ni siquiera se nos ha dado una explicación, deducimos que como entre la gente que viene hay alguien encargado de "formar las cooperativas" en consecuencia tenemos serias dudas que se cree una cooperativa oficial que también se usaría con otros fines, sobre todo en lo referente a créditos, a la que se harian aportes oficiales, liquidando la nuestra y reorganizándola por simpatias, vale decir, discriminando" (carta del 27 de septiembre de 1966, El Siglo 8/11/66).

En tanto, su esposa como forma de acercarse más a las mujeres y trabajar directamente con ellas, fundó un centro similar al del Centro de Madres de la Isla, al que se se le atribuyó un cierto matiz político y recibió el nombre de "Irene Frei".

En el imaginario nativo la figura de Rogers despierta fuertes antagonismos al momento de recordar su accionar tanto público como privado. Para algunos isleños, el gobernador estuvo influenciado en forma negativa, por funcionarios continentales como también por ciertos isleños, o "pascuenses chupamedias" (sic). El creyó que ser Gobernador era bogar para un sólo lado, resulta que el Gobernador es de la Isla (testimonio, véase Grifferos 1997).

A estos factores, cabe agregar que el escenario político de la época marcó las diferencias entre el Gobernador y los isleños que no compartían su doctrina política. En su desenvolvimiento como funcionario público, fue increpado por la comunidad por 
ejercer en estado de ebriedad, de desatender derechos y obligaciones y de discriminación política, por ofrecer empleo a isleños que apoyaban su ideario político:

"A la mayoría de esas personas se las mantiene en el plan de división gracias a puestos muy bien rentados que realmente no merecen debido a su enorme ignorancia. Por ejemplo, el caso de Florencia Atán, mujer muy odiada en la Isla, fue colocada como secretaria de la CORFO y no sabe ni escribir una carta. Gana dos millones de pesos al mes" (Carmen Cereceda, El Siglo 6/1/1967).

Se le acusó además, de destruir uno de los pilares fundamentales de la comunidad rapanui, es decir, "destruir la unidad y la tranquilidad de la familia pascuense, ejemplarmente mantenida por ellos a través de generaciones..." En todos los tonos y niveles los isleños afirman: "Rogers ha dividido nuestra familia", y esto, para el pascuense, es realmente un crimen (Réplica, 1967:4).

La efervescencia de esta antipatía al Gobernador, pudo estar influenciada por el gran carisma que caracterizó a Rapu,

"la población estaba latente y eufórica con Alfonso Rapu, estaban en contra de la persona que iba a dirigir los destinos de Isla de Pascua, se oponian, Rogers no supo respetar a los pascuenses, no fue prudente, impuso lo que quiso" (Testimonio; véase Grifferos 1997).

\section{El desembarco en la Bahía de Hanga Piko}

Una mañana de diciembre de 1967 , los inmutables moai despertaron del letargo y se acogieron al grito encarnizado de una comunidad que estaba siendo quebrantada en sus costumbres. La llegada del Gobernador Enrique Rogers en la motonave Navarino, rompería el tradicional esquema de bienvenida que se suele ofrecer en esa tierra, es decir, el acogedor recibimiento con flores de bouganvillia, esta vez fue reemplazado por piedras, insultos, atropellos, apaleos, entre otras manifestaciones.

Unos de los motivos que ocasionó tal bienvenida, se suscitó porque al momento de inscribir a los candidatos para regidores se aplicó el modelo de legislación continental, por tanto, se les exigía a cada candidato por lo menos 200 firmas de personas con domicilio conocido, no considerando que la población nativa ascendía aproximadamente a las 1200 personas (véase Cristino et al. 1984). Producto de esto, el único partido que tendría derecho a llevar candidato sería el Demócrata Cristiano por estar inscrito en el Registro Electoral y en pleno ejercicio del poder, de este modo Rogers sería el único candidato, en desmedro del candidato rapanui, $\mathrm{Al}$ fonso Rapu.

Los isleños por su parte, argumentan que Rogers no podía volver a la Isla por tres razones fundamentales: por la pérdida de documentos que entregaban personalidad jurídica a una cooperativa isleña; al no considerar el parecer de los todos isleños al momento de implementar medidas administrativas en la Isla, sino que sólo consultó a los rapanui de su Partido y finalmente de producir diferencias políticas entre los isleños (véase Sumario 1967).

Además exigió a los rapanui la entrega de tierras que a él le parecían adecuadas para edificios públicos o caminos, "terrenos para caminos, para plazas y hasta para los norteamericanos están siendo cedidos voluntariamente por los pascuenses" (Réplica, 1967: 4). Esta situación fue confirmada por los propios rapanui en la carta enviada al Presidente del Senado y de la Cámara en que se expresa que

"por ningún motivo permitiremos que se nos despoje impunemente de nuestras tierras y propiedades. Todo se puede hacer con un buen criterio y entendimiento, las compensaciones que nos prometen son sólo promesas y para nosotros no tendrán un valor real hasta que no veamos realidades y hechos. El año pasado al nativo Moises Tuki se le quitó su parcela para hacer la antena Radio-faro, se le prometió entre otras cosas hacerle una casa y mil cosas más, la Antena es ya una realidad, y las promesas lógicamente hechas de palabras, como lo exige la habilidad de un político, ahi están todavía en espera de la casa. Para la construcción de un grupo escolar, se le quitó un pedazo de terreno a doña Elodia Pakarati, prometiose lo mismo más un terreno en uno de los extremos de la Isla; aún no hay nada, y la Escuela ya está en plena construcción" (véase carta del 27 de septiembre de 1966, El Siglo $8 / 11 / 66)$ ).

A esto cabe agregar que Rogers amparaba abiertamente la presencia norteamericana en la Isla. En un diario de la capital se advertía esta situación 
detallándose que Isla de Pascua era: "puente para barcos yanquis que van al Vietnam" (Réplica 1967).

Los incidentes del 16 de diciembre, comenzaron cuando la lancha que traía al Gobernador desde la Motonave Navarino se acercaba a la Bahía de Hanga Piko, para recibir la tradicional bienvenida por un grupo folklórico de la Isla, sin embargo, un grupo de contramanifestantes comenzó a gritar ¡Andate Rogers, no te queremos en la Isla!, entre otras expresiones de repudio y trataron de avanzar hasta donde se encontraba el Gobernador, pero carabineros les cerró el paso.

Un grupo de mujeres abordó al Gobernador para decirle: "tú nunca nos ha recibido, ni como centros de madres, ni como mujeres", Rogers se molestó y dio algunas órdenes al grupo de casi 40 carabineros. Pero una isleña rompió el cordón policial y valientemente le dijo al Gobernador: "aunque no nos quieras oír, lo que queremos decirte es que nada tienes que hacer aquí. Ahí está el Navarino, vuélvete". De inmediato empezó el violento apaleo contra las mujeres. El primero en la historia de Isla de Pascua (El Siglo 3/1/1967).

La percepción rapanui de este hecho es fundamental para detectar los elementos de etnicidad presentes en el discurso

"el señor Cerda me tomó de los cabellos y me los tironeó, produciéndome una lesión en el cuello. Acudí al médico quien me examinó y me dio un remedio para el dolor. También los carabineros me echaron al suelo y golpearon. Yo no me acerqué al señor Gobernador, ni presencié que nadie lanzara piedras ni que fuera tomada por la solapa de la chaqueta" (Sumario 1967).

"Rogers, ándate", fue una clara evidencia de la comunidad rapanui para manifestar el rechazo por la forma en que el Gobernador estaba administrando la Isla. Sin embargo, estos hechos que fueron considerados por la prensa como extremadamente graves, el gobierno legitimó la acción de la fuerza pública como una forma de contener a los agitadores, que de preferencia lo conformaban mujeres (véase Aquí Está 11/1/1967). Las mujeres se defendieron argumentando que la contramanifestación no había sido planeada y que los incidentes tomaron tal matiz por la forma en que ellas fueron contenidas por carabineros.
La pintora Carmen Cereceda declaró en esa época que efectivamente hubo golpes a mujeres rapanui,

"una niña Rapu, fue a dar al Hospital sin conocimiento. Vi los machucones y las pinchadas en las piernas de las mujeres, en una reunión que hicieron en la tarde del mismo día. El caso más dramático es de Ester Haoa, en cuya casa yo pagaba la pensión. Es la esposa de uno de los mejores talladores de la Isla. Cuando llegué almorzar la encontré en cama, casi sin conocimiento, con dolores horribles al estómago. Le pregunté que le pasaba y contestó que el Gobernador suplente, Julio Zepeda, le habia dado un feroz puñete en el estómago" (El Siglo 9/ 11/66).

Sergio Rapu, hermano de Alfonso, se atrevió a hablar y afirmó categóricamente que él vio a las mujeres pascuenses golpeadas por carabineros, entre ellas Ursula Rapu y Rosa de Fati. A la primera de unos 26 años, le quebraron un diente y a la segunda, que tiene 50 años la hirieron en una pierna con un sable o bayoneta (El Siglo 5/1/67).

En este movimiento los isleños se dividieron en dos grupos; uno que apoya la posición del Gobernador y el otro que dirige Alfonso Rapu. Cabe destacar, que Rapu tal como había sucedido en el movimiento de 1964, se ocultó en algún lugar de la Isla por temor a ser llevado detenido al no compartir la ideología de Rogers y más aún de levantar una campaña paralela a la del Gobernador. Para estos fines contó con la ayuda del constructor civil Mario Olivares ${ }^{11}$, el generalísimo de su campaña a regidor.

Sergio Rapu, en una entrevista otorgada al diario El Siglo argumentó que la campaña desatada por el Gobernador hacia su hermano ha tomado connotaciones negativas. Había una orden de detención contra Mario Olivares, por tanto, ellos resolvieron proteger su integridad y decidieron esconderse, así esperarían los futuros acontecimientos.

Del grupo que apoya a Rogers, alrededor de 126 pascuenses le enviaron una carta al Presidente Frei, la que fue publicada por un diario de la capital y que detallamos a continuación:

11 Mario Olivares había sido designado por el Ministerio de Educación para trabajar en la construcción de la Escuela de Hanga Roa. Mario Olivares fue el Jefe de campaña de Alfonso Rapu en su período eleccionario para alcalde. 
"Querido Señor Presidente: Mucho nos ha extrañado el artículo aparecido en algunos diarios de Santiago, ya que de lo narrado, nada es verdad; nosotros los isleños, leales al gobierno de Chile -- que somos la gran mayoría-- estamos felices por su ayuda que nos está enviando, pero el grupo que envió carta diciendo mentiras, son elementos comunistas que no desean pertenecer a Chile". (Las Ultimas Noticias 5/1/1967).

Agregando además,

"que existen grupos beligerantes, encabezados por Alfonso Rapu, que desconocen a todas las autoridades, están formados por leprosos y analfabetos que están dispuestos a entregar la Isla a Francia".

El subsecretario del interior de aquel entonces, Enrique Krauss reiteró que de acuerdo con las informaciones oficiales de carabineros no ha habido actos de violencia alguno de la policía contra la población isleña, como ha estado informando un diario de la capital. Desmintió los incidentes en la Isla y declaró que carabineros no habían intervenido sino "contenido" la manifestación. Sin embargo,

"Ia reportera Ximena Cannobbio, del canal 9, puso encima del escritorio del Subsecretario, una foto de los incidentes en la Isla de Pascua. El Subsecretario del interior, quedó definitivamente mudo...después de instantes que se hicieron tensos, sólo atinó a decir: ¿Esto es de Pascua...? La molestia del Subsecretario fue evidente. De inmediato expresó que pediría complementación de antecedentes" (El Siglo 4/1/1967).

El movimiento suscitado en la bahía de Hanga Piko a fines del año ' 67 , tuvo carácter de desorden y desacato por lo que fue necesario implementar un sumario por la responsabilidad que competía tanto a isleños como a carabineros. A juicio del Gobernador Rogers,

"los incidentes referidos fueron producidos con la activa dirección del Cabo de la Armada Hugo Arancibia Ramírez, de la dotación de la Capitanía de Puerto local, a quien numerosos testigos vieron que efectuaba señales inequívocas desde la embarcación en que venía el suscrito. El Cabo Arancibia desechó además las indicaciones que le hiciera el Capitán Ayudante de la Gobernación, don Carlos Gallegos Parra, en el sentido de que atracara en un lugar del muelle que se encontraba despejado de gente a fin de evitar desórdenes, haciéndolo por el contrario en el lugar donde se encontraba el grupo hostil, con el objeto evidente de provocar el desacato de que fue objeto el Gobernador infrascrito" (véase Sumario 1967).

Por su parte, el rapanui que llevaba la barcaza con el Gobernador está procesado por la responsabilidad que el atañe en este hecho, al conocer las intenciones que tenían las mujeres contramanifestantes y no haberlo comunicado a su superior.

Intereses, posiciones, tácticas y estrategias

En el movimiento de 1966 está explícita la idea de una comunidad que sea respetada en sus costumbres, por tanto la persona que guíe los destinos de Rapanui, debe conocer a cabalidad su idiosincracia, es así como en el imaginario nativo la idea de imposición y sometimiento atenta contra la integridad comunitaria.

En Isla de Pascua la estructura de intereses tiende a oponerse, es decir, para la comunidad rapanui existe en la Isla una situación tanto política como económica desfavorable con respecto al Estado Chileno. Existían problemas de representación al interior de la comunidad al polarizarse en dos grupos, es decir, uno que encabezaba Rogers y otro que lideraba Rapu con el apoyo mayoritario de la comunidad rapanui. El elemento común en ambos grupos era el respeto a sus tradiciones por sobre intereses político-partidista, sin embargo, las mujeres adoptaron una estrategia más confrontacional al declarar abiertamente su repudio por el accionar ya sea público como privado del Gobernador.

El grupo liderado por mujeres rapanui utiliza la táctica de la rebelión como forma de recrear elementos de etnicidad. Se oponen a todo orden impuesto coercitivamente. Para ellas es digno protestar y apropiarse de espacios como la bahía de Hanga Piko para canalizar sus demandas, era el momento preciso para que la televisión y la radio se convirtieran en fieles testigos de los futuros sucesos.

El grupo liderado por Rogers tiene como estrategia apoyar el accionar del Estado Chileno en la Isla y catalogar de "comunistas" al bando contrario por el sólo hecho de provocar desordenes y por no compartir la ideología de Rogers. 
El atentado al Gobernador Rogers se convirtió en una "estrategia de grupo" a juicio de Bourdieu (1991, 1997). Para el autor las estrategias son reconocibles con relación a las estructuras (posibilidades objetivas de acción) y a los habitus (disposiciones duraderas incorporadas a los actores ajustadas a las posibilidades de acción). Al aplicarlo al contexto rapanui las mujeres encontraron el escenario propicio, tal es, una bahía que se convirtió en el espacio de "rapanuización" el que no obstante, poseía resguardo policial, no fue un impedimento para cortar el cordón y abalanzare contra Rogers para enjuiciarlo públicamente. Para ellas fue una acción legítima y que guardaba estrecha relación con un comportamiento racional.

Es aquí donde está implícita la idea de incertidumbre que mueve a los actores sociales. El Movimiento de las mujeres puede desaparecer para el fin que fue creado, por esto toda organización es incierta, incluso ni el propio discurso está estructurado totalmente.

El Juzgado de Letras de Rapanui al implementar el Sumario contó con un amplio poder judicial para procesar a quienes incitaron los incidentes, sin embargo, la comunidad ejerce mayor influencia apropiándose del discurso de las propias autoridades que los juzgaban, es decir, ellos manifestaron que su participación en los hechos, se debió al "engaño de provocadores de mayor formación educacional" (véase Sumario 1967).

Los isleños frente a los escasos recursos que poseen frente a un escuadrón de uniformados son capaces de detener un conflicto armado por el simple hecho de hacer suyo el discurso de la "rapanuización" de la Isla. La relación de poder frente a los continentales los sitúa en considerable ventaja. Se produce tal reciprocidad de comportamientos que entre ambos bandos involucrados (isleñosfuerza pública) se termina generando un cierto control que les permite quedar en igualdad de condiciones.

El recurso a la devolución de las tierras nuevamente queda de manifiesto, por la actitud que asume

12 El recurso a la devolución de las tierra ha formado parte de los movimientos o levantamientos que sacudieron a Pascua en el siglo pasado.
Rogers al intentar implementar una reforma urbanística en la Isla, sin el previo conocimiento y consentimiento de la comunidad rapanui. Algunos isleños mediante engaños, fueron obligados a ceder sus terrenos como forma de satisfacer las medidas de Rogers. Retomando el planteamiento de Burrigde (1969), en el mundo polinésico ésta es generadora de prestigio, es decir, existe un ingreso igualitario a los recursos lo que permitía generar criterios de integridad de manera de evaluar a los individuos (véase Grifferos 1997). En el trasfondo de los conflictos acaecidos en la Isla la idea de la tierra persiste y la comunidad insiste en que ésta les fue robada ${ }^{12}$, sin embargo, el Estado chileno vislumbra la reivindicación de la tierra con fines políticos. Aún más,

"la tierra es el lazo de unión del sistema y también es el factor que origina conflictos entre personas que comparten una descendencia genealógica pero no emocional. El código legal de Chile dice que sólo el Estado tiene títulos sobre la Tierra, pero muchos isleños no lo aceptan" (McCall 1996: 44).

La negociación llevada a cabo en este conflicto estuvo atravesada por el tema del poder, para ello nos remitimos al planteamiento de Crozier, quien señala que el poder es una relación y no un atributo de una autoridad o de los propios actores:

"La fuente principal de poder corresponde a las posibilidades de acción de cada actor. El poder reside en el margen de libertad del cual dispone cada uno de los actores comprometidos en una relación de poder, es decir, en la posibilidad más o menos grande de rechazar lo que el otro le demanda" (véase Crozier 1977).

Nos atrevemos a afirmar que todos los actores sociales involucrados manejaron su propia lógica del poder, logrando de esta forma controlar su accionar y el de sus adversarios. Como el caso del Movimiento de las mujeres, cualquier otra organización que intente levantarse contra el Estado Chileno está sometido a un mar de particularidades e intereses diferentes, lo regirá la contingencia, es decir, todo aquello que puede llegar a suceder en un momento determinado. Es importante destacar además, cómo los rapanui se apropian de estrategias que los benefician, sin embargo, el problema de trasfondo en este conflicto es la situación colonial como quebrantadora de la comunidad rapanui. 
Para el mundo rapanui, lo que se manifiesta al interior de su comunidad es una revitalización cultural. Los isleños lejos de considerarse diferentes históri- ca y culturalmente, exigen autonomía y abogan por la defensa de sus derechos ya sea por la vía de la fuerza o la vía política.

\section{BIBLIOGRAFIA}

ABERCROMBIE, T., 1991. Articulación doble y etnogénesis in Frank Salomon et al. (comp.) Reproducción y transformación de las sociedades andinas. Ed. Abya Yala, Quito, Ecuador, pp.197-212.

BERGER, P. L. y LUCKMANN T., 1971. The social construction of reality. Penguin University Books, Gran Bretaña.

BONFIL, G., 1988. Identidad étnica y movimientos indios en América Latina, en Identidad étnica y movimientos indios. La cara india, la cruz del 92. Editorial Revolución, Madrid.

BOURDIEU, P., 1991. El sentido práctico. Taurus, Madrid.

----- 1997 ¿Es posible un acto desinteresado?, en Razones prácticas, sobre la teoría de la acción, Editorial Anagrama, Barcelona. pp. 139 - 158.

BURRIDGE, K., 1969. Nuevo cielo, nueva tierra. Un estudio de actividades milenarias. Editorial Tiempo Nuevo, S.A., Caracas.

CRISTINO, C., 1984. et. al. Isla de Pascua: Proceso, alcances y efectos de la aculturación Universidad de Chile, Facultad de Arquitectura y Urbanismo.

CONSEJO DE ANCIANOS RAPANUI Y GRUPO GEA., 1990. Conclusiones preliminares del Primer Congreso para el Desarrollo de Isla de Pascua. Hanga Roa 8-9-10 y 11 de febrero.

CROZIER, M., 1977. L' organisation comme probleme, en $L^{\prime}$ actuar et le systema. Seuil, París, p. 41 - 127.

DELSING, R., 1988; et.al. Relaciones de género en Isla de Pascua, una sociedad multicultural en cambio. Proyecto FONDECYT N ${ }^{\circ} 1960146$

DEVALLE, S., 1992. La etnicidad y sus representaciones: ¿juego de espejos? en Estudios Sociológicos, El Colegio de México, enero-abril 28: 31-52.

EVANS, H., 1965. A world away. A canadian Adventure on Eastern Island. The Ryerson Press, Toronto, Canadá.

GALLEGUILLOS, 1974. Tama te ra'a o Pascua, Isla del Sol Naciente. Editores Hergon Libros, Santiago, Chile.

GRIFFEROS, A., 1997. La otra cara del paraíso. Comunidad, Tradición y Colonialismo en Rapanui 1864 - 1964. Tesis para optar al Grado Académico de Licenciada en Historia.
LEVI STRAUSS, C., 1964. El pensamiento salvaje. Editorial Fondo de Cultura Económica, México.

McCALL, G., 1975. Shorter Communications: Sympathy and antipaty in Easter Islander an Chilean Relations in The Journal of the Polynesian society, The Polynesian Society, University of Auckland, New Zealand, V. $84 \mathrm{~N}^{\circ} 4$, pp. 467476.

--1994a. Rapanui and Chile. An example of land and colonialism from the Pacific in Indigenous affairs, International Work Group for Indigenous Affairs, Copenhague $\mathrm{N}^{\circ}$ 4: $32-39$.

--- 1994b. Rapanui tradition survival on easter island. Second Edition, University of Hawaii Press, Honolulu. Traducido por Betty Haoa Rapahango.

----1 1996 El Pasado en el presente de Rapanui, Isla de Pascua en Jorge Hidalgo et al. (Eds.) Etnografía, sociedades indígenas contemporáneas y su ideología, Ed. Andrés Bello, Santiago.

METRAUX, A., 1950-1971. La Isla de Pascua Editorial Fondo de Cultura Económica. México-Buenos Aires. Ethnology of Easter Island (Bernice P. Bishop Museum Bulletin 160 Honolulu, Hawaii)

PORTEOUS, D., 1981. The modernization of easter island. Western Geographical Series, Vol 19. Department of Geography, University of Victoria. Victoria, British Columbia, Canada. Editorial Addres.

REDFIELD, R., 1963. El Mundo Primitivo y sus Transformaciones, Fondo de Cultura Económica, $1^{\text {a }}$ edición español, México-Buenos Aires.

RUVALCABA, J., 1995. De ebrios, flojas, locos, sucias y reincidentes. Formas de control social en la Huasteca, en Chenaut, Victoria y Sierra, María Teresa (Edits.) Los pueblos indigenas ante el derecho. Ciesas, Centro Francés de Estudios Mexicanos y Centroamericanos.

SILVA, J., 1980. El problema Hangaroa en Revista de Educación y Cultura, Secretaría Regional Ministerial de Educación, Valparaíso, Chile, Año III, pp. 25-27.

THOMPSON, E., 1984. La Economía Moral de la Multitud en la Inglaterra del siglo XVIII, en Tradición Revuelta y Conciencia de Clase. Editorial Crítica, Grupo Editorial Grijalbo, Barcelona, $2^{\mathrm{a}}$ edición. 
SUMARIO: JUZGADO DE LETRAS DE ISLA DE PASCUA

Denunciante: carabineros.

Denunciados: María Pua Pakomio y 27 más.

Delito: Desorden (falta 16.571).

Fecha de iniciación: 16 de diciembre de 1967

Rol No 29.

Juez: Alberto Rubio Riesco.

Secretario: Iván Katalinic Sánchez.

\section{Publicaciones Periódicas}

Aquí Está Miércoles 11 de enero de 1967, Santiago.

Réplica $1^{a}$ Quincena de enero de 1967, Santiago.

El Siglo 7-8-9 de noviembre de 1966. 3-4-5-6-7-8 de enero de 1967 , Santiago.

La Nación: 2/2/65, Santiago.

La Unión Domingo 8 de enero de 1967, Santiago. 
